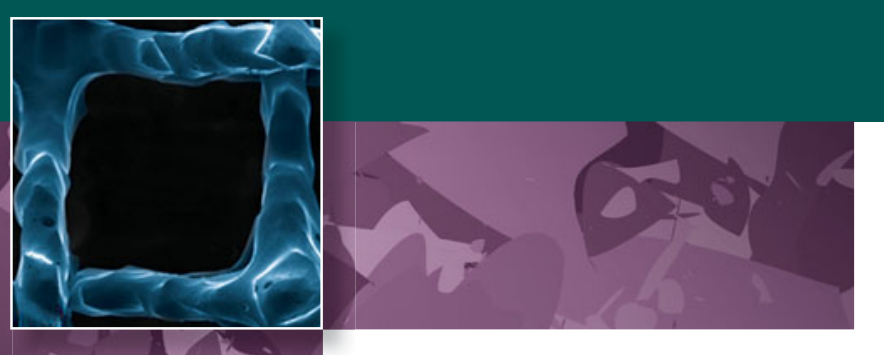

\title{
Laser additive manufacturing of bulk and porous shape-memory NiTi alloys: From processes to potential biomedical applications
}

\author{
Sasan Dadbakhsh, Mathew Speirs, Jan Van Humbeeck, and \\ Jean-Pierre Kruth
}

NiTi alloys are well known not only due to their exceptional shape-memory ability to recover their primary shape, but also because they show high ductility, excellent corrosion and wear resistance, and good biological compatibility. They have received significant attention especially in the field of laser additive manufacturing (AM). Among laser AM techniques, selective laser melting and laser metal deposition are utilized to exploit the unique properties of NiTi for fabricating complex shapes. This article reviews the properties of bulk and porous laser-made NiTi alloys as influenced by both process and material parameters. The effects of processing parameters on density, shape-memory response, microstructure, mechanical properties, surface corrosion, and biological properties are discussed. The article also describes potential opportunities where laser AM processes can be applied to fabricate dedicated NiTi components for medical applications.

\section{NiTi shape-memory alloys}

Shape memory is a fascinating material property, enabled by complex deformation mechanisms that create the "shape memorizing" ability in specific metallic and polymeric materials. Shape-memory materials can recover their primary shape after deformation (applied under specific temperature/ stress conditions) as a response to a thermal or mechanical command. This capacity of shape-memory materials allows for a wide range of applications, from biomedical implants and devices to sensors, actuators, aerospace components, and even fashion items. ${ }^{1-6}$

This article focuses on NiTi (nickel titanium or nitinol) intermetallics, since they are the most utilized shape-memory alloy. NiTi intermetallics are ductile in contrast to commonly known brittle intermetallics, hence they are commonly referred to as alloys. NiTi alloys regain their original shape through a reversible martensitic transformation (i.e., low-temperature martensite $\leftrightarrow$ high-temperature austenite) (see Figure 1). ${ }^{7-9}$ The low-temperature martensite deforms through reorientation and detwinning of martensite lattice structure. Subsequent heating transforms the martensite (monoclinic with low symmetry) to austenite (body-centered cubic with high symmetry) and recovers the original shape. This type of shape-memory effect is also known as a thermal-memory effect.

Conversely, when the austenite is stressed within a specific temperature range, it transforms to martensite. Since martensite is unstable without stress at those temperatures, it transforms back to austenite upon unloading, reversing the deformation. This results in a large elastic response, called superelasticity. ${ }^{10-13}$ Accordingly, the martensite $\leftrightarrow$ austenite transformation temperature is the most important factor in NiTi alloys; it defines the application at an intended working condition.

Besides the shape-memory ability of NiTi alloys, they exhibit other valuable characteristics (e.g., good biocompatibility [comparable to conventional stainless steel and titanium, despite some existing concerns]), ${ }^{14-17}$ low stiffness (important for biomedical applications where bone stress shielding or bone healing is an issue), ${ }^{18,19}$ good corrosion resistance (similar to 300 series stainless steel or titanium alloys), ${ }^{20,21}$ superb wear resistance, ${ }^{22-24}$ high strength, and excellent ductility. ${ }^{22,25}$ These characteristics broaden the applications and performance of NiTi devices. 


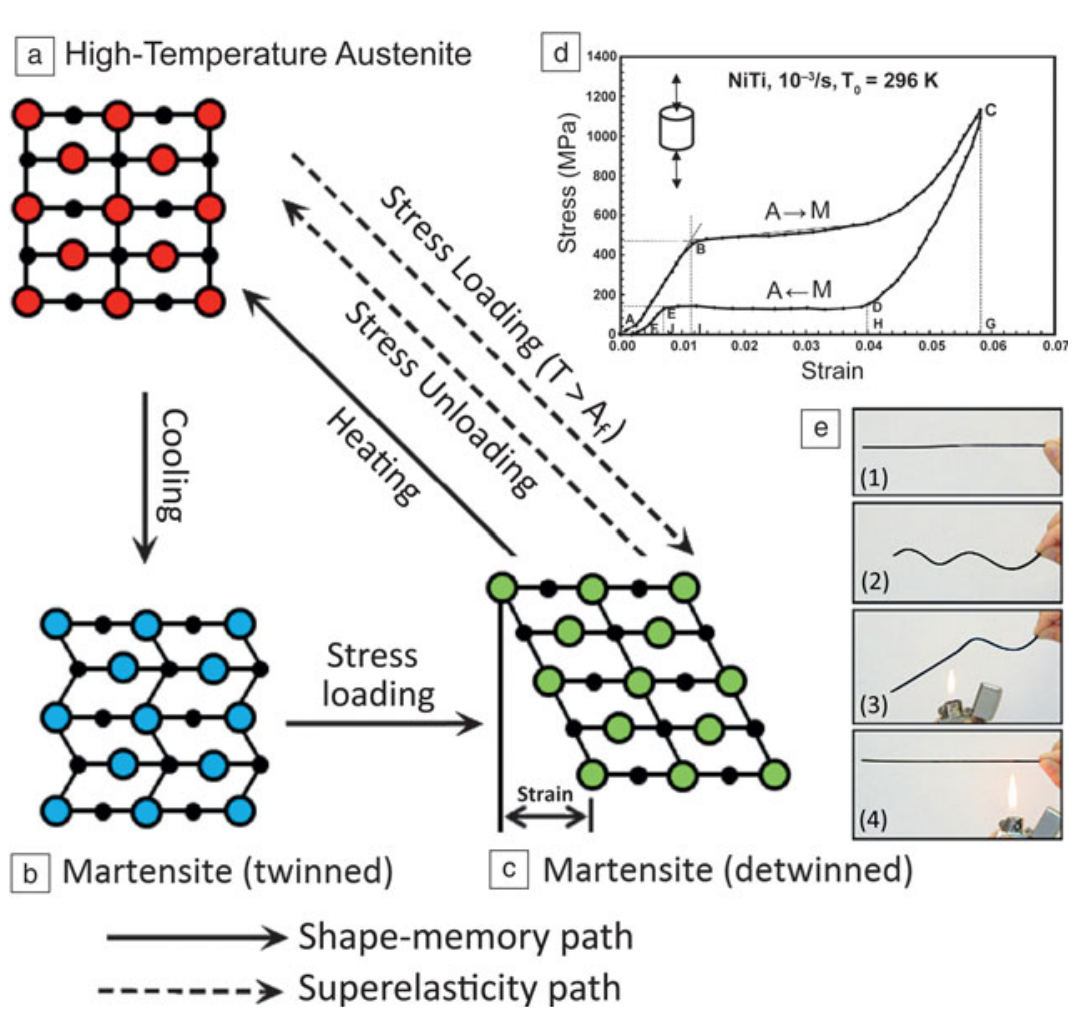

Figure 1. (a-c) Schematic illustration of the mechanism of the shape-memory effect and superelasticity. (d) Stress-strain curve showing superelasticity in a NiTi alloy at a temperature above $A_{f}$ (the temperatures at which austenite becomes fully stable). (e) Visual observation of the shape-memory effect in a NiTi wire: (1) original wire in the austenite phase; (2) deformed wire (at martensite phase); and (3-4) regaining the original shape upon heating to a temperature above $A_{\mathrm{f}}{ }^{7}$ Reprinted with permission from References 8 and 9. () 2014 IOP Publishing and (c) 2006 Elsevier, respectively.

it is to achieve a dense part in complex shapes; and with conventional machining, it is the severe tool wear due to the highly abrasive and elastic nature of NiTi. In contrast, laser AM methods are able to produce homogeneous compositions in complex and dense components without any extensive machining or expensive and complex dies. Laser AM techniques are thus increasingly being applied to manufacture NiTi components in bulk and porous geometries.

The two main laser AM techniques to fabricate complex NiTi components are (1) selective laser melting (SLM) ${ }^{13,29,36-41}$ and (2) laser metal deposition (LMD). ${ }^{42-45}$ Both of these methods are used to manufacture three-dimensional (3D) parts from metal powders, by a layer-wise manner from individual cross sections sliced from a computer-aided design model. SLM, for instance, melts and solidifies selected regions on a metal powder bed layer by layer (see Figure 2a). ${ }^{46}$ However, LMD methods feed successive layers of powders through a nozzle (or several nozzles) onto the build surface, where the powder is melted upon laser exposure (Figure 2b), ${ }^{47}$ until a 3D component is delivered.

In both SLM and LMD, several material, machine, and process parameters need to be carefully selected. Apart from material parameters (such as powder morphology and composition) and machine characteristics

Several factors can affect the performance of NiTi alloys. The most influential is the alloy composition; a sample of NiTi alloy contains nominally 54.5-57 wt $\% \mathrm{Ni}$ (equates to about $49.4-51.9$ at. $\% \mathrm{Ni}) .{ }^{26}$ The slightest change in $\mathrm{Ni}$ content can vary the martensite $\leftrightarrow$ austenite transformation temperature. ${ }^{27,28}$ In addition to composition, manufacturing parameters can affect lattice defects, grain structure, texture, precipitates, or even surface conditions that can alter the material performance. ${ }^{29-31}$ This article gives a brief review of the current knowledge on the effects of laser additive manufacturing (AM) parameters on the properties of NiTi alloys. The goal is to engineer desirable performance in complex components based on the final application requirements.

\section{Laser AM techniques for fabricating NiTi components}

NiTi alloys are conventionally fabricated through casting (usually under vacuum), metal forming (e.g., cold or hot rolling), powder metallurgy routes (e.g., sintering, self-propagating high-temperature synthesis), and machining processes. ${ }^{22,32-35}$ The challenge with casting is to obtain a uniform and homogeneous NiTi composition; with metal forming, it is to deform the specimen into specific shapes; with powder metallurgy, (such as laser type and atmosphere), processing parameters such as laser power $(P)$, scan speed $(v)$, track spacing $(h)$, scanning pattern, powder-layer thickness $(t)$, beam-spot diameter $(d)$, and powder feed rate (only in LMD) affect the final quality of the manufactured part. The combined influence of these parameters on the main quality factors of AM parts (most importantly, material density) is commonly expressed as an engineering parameter called laserenergy density $(E)$. This is shown in Equation 1 for SLM and Equation 2 for LMD:

$$
\begin{aligned}
& E_{\mathrm{SLM}}=P / v h t, \\
& E_{\mathrm{LMD}}=P / d v .
\end{aligned}
$$

\section{Manufacturing parameters for dense NiTi components}

Porosity has been identified as one of the main quality issues in AM processes. ${ }^{48}$ The first step to manufacture NiTi parts using SLM or LMD is to maximize material density. Table $\mathbf{I}^{13,29,36,38,40,49-55}$ and Table II $^{42,45,56-59}$ summarize the processing parameters to manufacture bulk NiTi components, according to reports in the literature. It is worth mentioning 


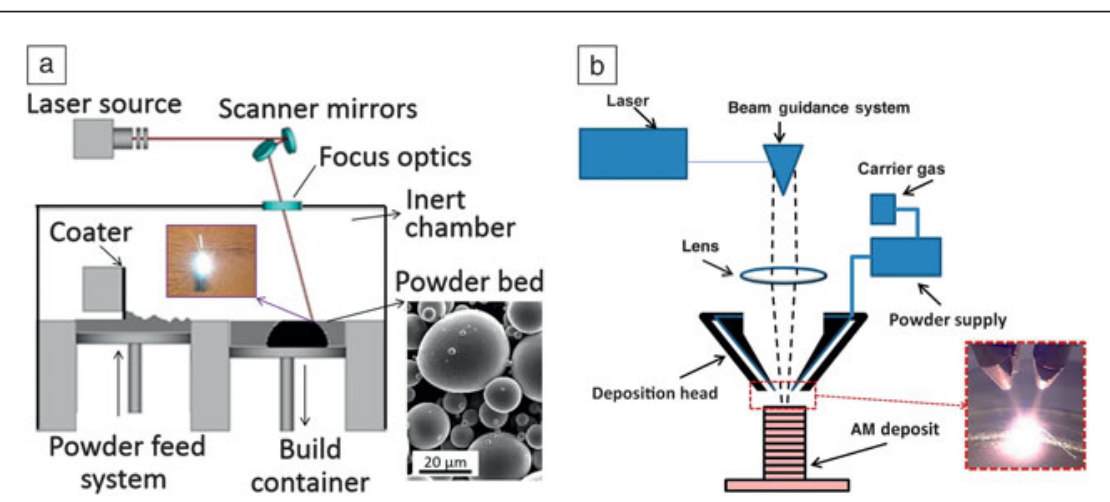

Figure 2. Schematics of (a) selective laser melting process, with a scanning electron microscope image of a typical powder (inset). Source: KU Leuven. (b) Laser metal deposition principle, with a photo of the metal deposition process (inset). ${ }^{47}$ Adapted with permission from Reference 46. (C) 2014 Macmillan Publishers Ltd.

Scan speed is one of the most important factors influencing the transformation temperature. A lower SLM scan speed can increase the transformation temperature (even at a comparable laser-energy density), stabilizing martensite. ${ }^{29}$ Higher SLM energy density is another factor that can increase the martensitic transformation, ${ }^{36}$ causing a better shapememory effect at a specific temperature. It should also be noted that a higher energy density may cause higher take-up of impurities (such as oxygen and nitrogen), ${ }^{55}$ hence it may reduce the shape-memory quality or influence the transformation temperatures. Overall, such shape-memory modifications (from laser processing parameters) are due to various material influences (e.g., elemen-

that in SLM, increasing the laser-energy density usually improves the component density until it reaches a maximum. After that, density may decrease in some cases, especially for materials susceptible to oxidation and evaporation. This is particularly important for NiTi alloys, where elemental evaporations can alter the desired chemical compositions and lead to an unexpected and random shape-memory behavior.

\section{Effect of processing parameters on NiTi martensitic transformation temperature}

As noted, processing parameters can be carefully selected to engineer the martensitic transformation temperatures, as the key factor determining the shape-memory response at the working temperature of the application. Besides the shapememory response, the martensite $\leftrightarrow$ austenite transformation temperature affects other properties, such as wear resistance and stiffness, which are inherently different for martensite and austenite.

In laser AM techniques, laser remelting of the powder can homogenize and eliminate local variations in composition and transformation behavior of the pre-alloyed NiTi powders (e.g., multiple-step transformation temperatures for the as-received powder can become a one-step transformation after SLM). This increases the shape-memory quality of the used powder. tal Ni evaporation, precipitation, grain size, thermal stress, and oxidation) as a result of different exposure conditions from the laser. ${ }^{29,36,42,55,57}$

\section{Microstructure and texture of processed NiTi alloys}

There are several microstructural characteristics correlated with the highly localized heating, fast heating rates, and rapid solidification associated with laser AM processes such as SLM. Although these characteristics vary depending on the parameters used, they may generally include laser solidification tracks, very fine austenitic grains (formed inside melting pools), thermal stress-induced martensitic phases appearing as large plates, and a preferential texture (according to heat flow direction). As a comparison between SLM and LMD, these characteristics are more accentuated in SLM where the scan speed can be orders of magnitude higher (see data in Table I and Table II).

As an example of the general microstructural characteristics of NiTi SLM parts, Figure 3a shows the perpendicular laser tracks (formed from the $90^{\circ}$ rotation of the scan pattern). The embedded large plates are associated with selfaccommodation of large martensitic features induced by large SLM thermal stresses (these strongly depend on the SLM

\begin{tabular}{|c|c|c|c|c|c|c|}
\hline Density & $\begin{array}{c}\text { Energy } \\
\text { Density }\left(\mathrm{J} / \mathrm{mm}^{3}\right)\end{array}$ & Power (W) & $\begin{array}{c}\text { Scan } \\
\text { Speed (mm/s) }\end{array}$ & $\begin{array}{c}\text { Powder } \\
\text { Thickness }(\mu \mathrm{m})\end{array}$ & $\begin{array}{c}\text { Track } \\
\text { Spacing }(\mu \mathrm{m})\end{array}$ & Comment \& Reference \\
\hline- & $\mathrm{N} / \mathrm{A}$ & 85 & 200 & $N / A$ & $\mathrm{~N} / \mathrm{A}$ & Only a single scan. ${ }^{49}$ \\
\hline- & $60-125$ & $56-100$ & $107-224$ & 50 & 120 & Characterization is targeted. 36,50 \\
\hline- & 56 & 250 & 1250 & 30 & 120 & 51,52 \\
\hline$>97 \%$ & $52-83$ & 50 & 100,160 & 60 & 100 & Performed with heating to $500^{\circ} \mathrm{C} .{ }^{40,53}$ \\
\hline$>99 \%$ & - & 100 & 200 & 50 & - & $\begin{array}{l}\text { SLM on elemental Ti and Ni powder. } \\
\text { Heated to } 80^{\circ} \mathrm{C} .{ }^{54}\end{array}$ \\
\hline$>99 \%$ & $111-126$ & 40,250 & 160,1100 & 30 & 75,60 & $13,29,38$ \\
\hline$>99 \%$ & $>64$ & 77 & 200 & 50 & 120 & 55 \\
\hline
\end{tabular}




\begin{tabular}{|c|c|c|c|c|c|c|c|}
\hline Density & $\begin{array}{c}\text { Energy } \\
\text { Density }\left(\mathrm{J} / \mathrm{mm}^{2}\right)\end{array}$ & Power (W) & $\begin{array}{c}\text { Scan } \\
\text { Speed (mm/s) }\end{array}$ & $\begin{array}{c}\text { Beam } \\
\text { Size }(\mu \mathrm{m})\end{array}$ & $\begin{array}{c}\text { Powder } \\
\text { Rate (mg/min) }\end{array}$ & $\begin{array}{c}\text { Layer } \\
\text { Thickness }(\mu \mathrm{m})\end{array}$ & Comment \& Reference \\
\hline- & 1200,400 & 30 & $0.83,2.50$ & - & - & 10 & Micro-LMD, elemental Ti and $\mathrm{Ni}^{45}$ \\
\hline$>99 \%$ & 850 & 30 & 1.17 & 30 & $0.76,1.26$ & $6-10$ & Micro-LMD, optimally heated at $300^{\circ} \mathrm{C}^{56}$ \\
\hline- & 40 & 250 & 12.5 & 500 & 5700 & 254 & $\begin{array}{l}\text { Pre-alloyed } \mathrm{NiTi} \text { as well as elemental } \\
\qquad \mathrm{Ti} \text { and } \mathrm{Ni}^{5}{ }^{7}\end{array}$ \\
\hline $97-98 \%$ & $20-80$ & $200,300,400$ & 10,20 & 500 & 4360 & - & 58 \\
\hline $96-98 \%$ & $53-131$ & 300,500 & 10,15 & - & 5500 & - & 42 \\
\hline$>99 \%$ & $25-60$ & 250,600 & 10,16 & $<1000$ & 6700 & 381 & 59 \\
\hline
\end{tabular}

parameters used). Formation of such features can mitigate the SLM residual elastic energy between the laser scan tracks, but it reduces the unity of martensitic transformations and hence the quality of the shape-memory response. ${ }^{13}$ In terms of the texture orientation, the grains have a tendency to orient toward the build direction (Figure $3 b$ ), which is also the direction of heat flow. ${ }^{36}$ This stimulates a significant anisotropy in the shape-memory response and the apparent stiffness. ${ }^{13}$ At higher magnifications, fine martensitic features (internally twinned after transforming from the high-temperature austenitic phase, Figure 3c) or fine austenitic subgrains due to high scan speeds (Figure 3d) can appear.
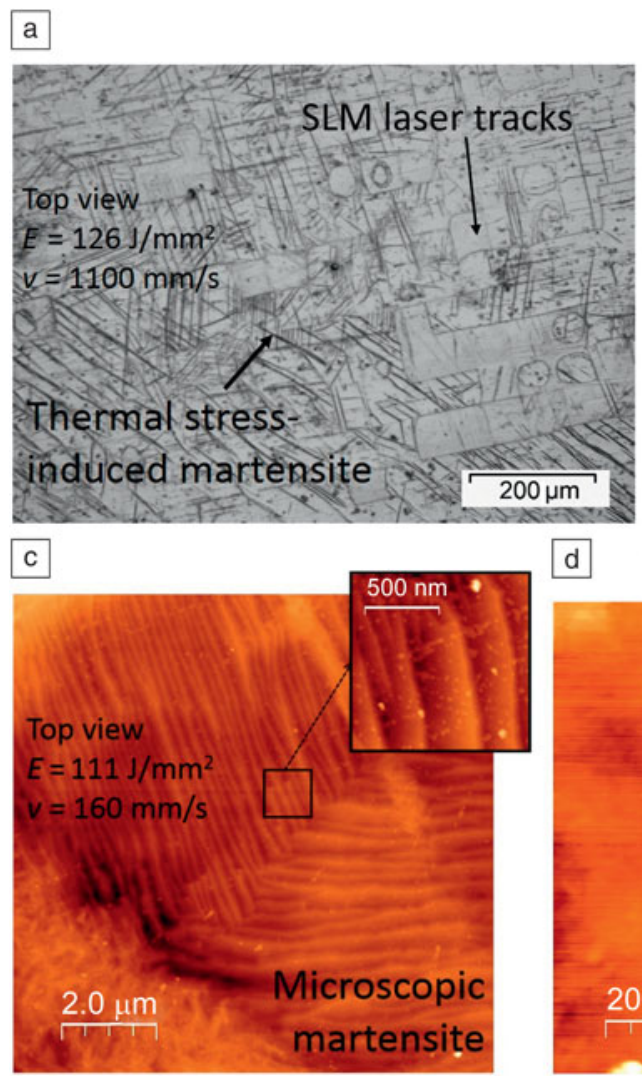

d

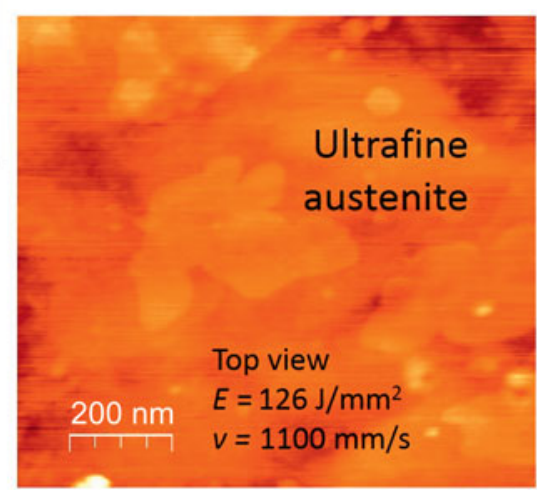

Figure 3. Microstructural features in NiTi selective laser melting (SLM) parts. (a) Optical microscope image of SLM laser tracks containing thermal stress-induced martensite forming when the laser thermal stresses are high. ${ }^{13}$ (b) Electron backscatter diffraction image from preferential texture and orientation of fine austenitic subgrains towards SLM build direction. (c) Atomic force microscope (AFM) image of fine, internally twinned martensitic structure (engineered with a set of SLM parameters that stabilize martensite). (d) AFM image of ultrafine $(\sim 350 \mathrm{~nm})$ austenitic subgrains (engineered with a set of SLM parameters that stabilize austenite). Note: $E$, laser-energy density; $v$, scan speed..$^{29}$ (b) Adapted with permission from Reference 36. @ 2012 Springer.

\section{Mechanical behavior and shape- memory response of bulk and porous parts}

Mechanical behavior and shape-memory response are direct outcomes of microstructural characteristics. Accordingly, a high-temperature austenitic phase results in superelastic behavior, in contrast to the martensitic phase that enables shape recovery after being heated to higher temperatures. For example, Figure 4a shows the compression behavior of a NiTi SLM part, where a low-temperature martensite phase leads to a significant thermal recovery (see the curve at $7^{\circ} \mathrm{C}$ ). Rather superelastic behavior occurs at higher temperatures when austenite becomes stable. ${ }^{51}$ By increasing the temperature beyond the superelastic window, austenite becomes more stable and cannot easily transform to martensite under loading, inhibiting the martensite $\leftrightarrow$ austenite transformation. This consequently reduces the superelasticity and shape-memory recovery (see the $47^{\circ} \mathrm{C}$ curve in Figure 4a).

Nevertheless, it is worth mentioning that superelasticity may not be fully effective in as-fabricated SLM parts, perhaps due to formation of stress-stimulated martensitic phase induced by laser thermal stresses (see Figure 3a). ${ }^{13}$ However, a stress-relieving posttreatment such as solution annealing, where the material is annealed at high temperatures and subsequently quenched to dissolve all precipitates, may allow complete superelastic behavior of the material (e.g., see $-5^{\circ} \mathrm{C}-15^{\circ} \mathrm{C}$ curve in Figure $4 \mathrm{~b})^{51}$ by annihilating these stress-induced martensitic phases. 


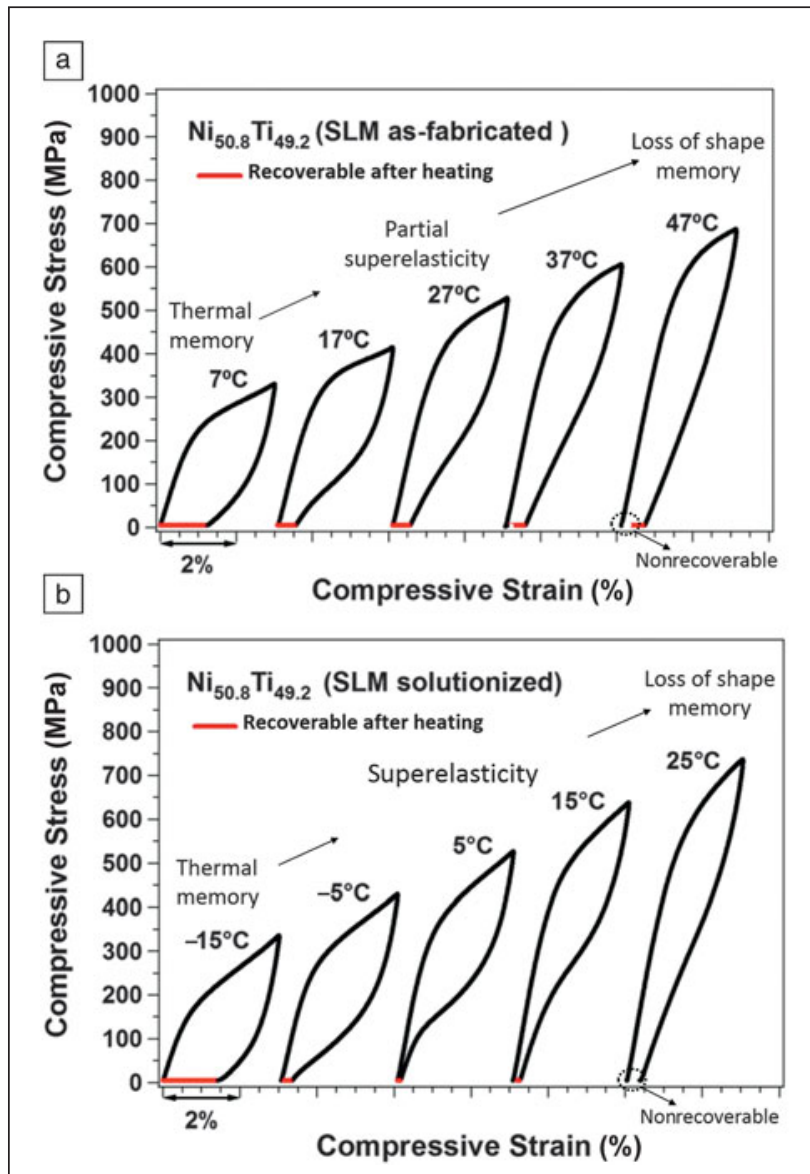

Figure 4. The compression behavior of a NiTi selective laser melting (SLM) alloy at different temperatures. (a) Before and (b) after solution treatment (quenched rapidly after heating at $950^{\circ} \mathrm{C}$ ). Note: superelasticity might not be fully accomplished in as-fabricated SLM parts, but solution treatment may increase the superelastic quality. Adapted with permission from Reference 51. (C) 2016 IOP Publishing.

One of the most interesting features of laser AM processes is the ability to manipulate the stable phase in NiTi alloys in order to engineer components. Figure 5 demonstrates how different SLM scan speeds can lead to superelasticity or, in contrast, thermal memory (e.g., recovery after heating is significantly more in SLM samples made by a lower scan speed).

In addition to bulk NiTi, porous NiTi alloys have been extensively studied because of their biomedical applications. Similar to the bulk material, the shape-memory response and the mechanical behavior of porous scaffolds can be manipulated using the AM laser parameters. Moreover, various solid volume fraction or porosity contents can be adjusted according to the load-bearing applications of the final implant (see Figure 6a, where uniformly deformed porous structures may provide different strengths).$^{38}$ Another important aspect is unit cell design of the porous structure that can control the shapememory response of the structure (Figure 6b).

In terms of fatigue response, superelastic NiTi displays superior fatigue life. ${ }^{60}$ Bernard et al. ${ }^{61}$ demonstrated that LMD-made

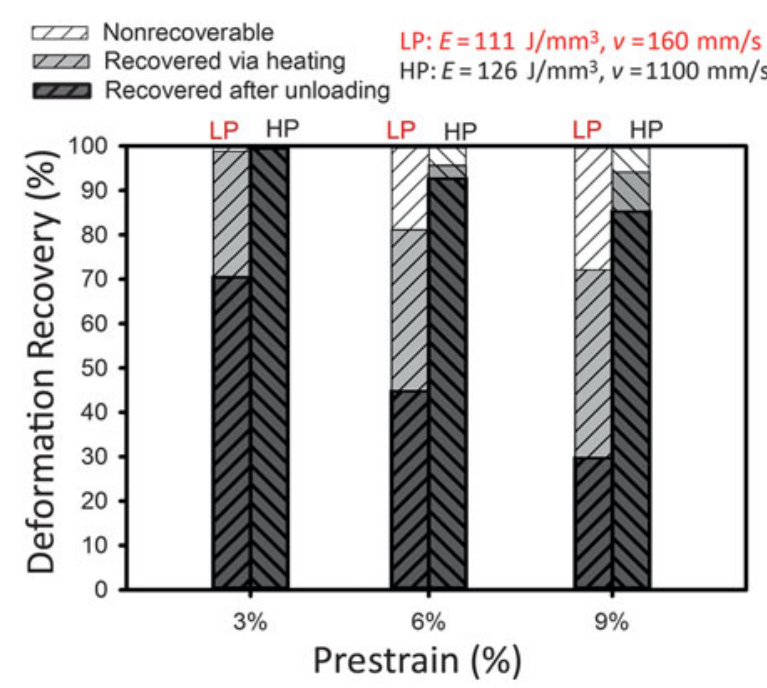

Figure 5. Deformation recovery after compression of NiTi selective laser melting parts made using different scan speeds $(v)$. Note: $E$, laser-energy density; LP, low power low speed; HP, high power high speed. Adapted with permission from Reference 29. (C) 2014 Wiley.

NiTi alloys (mostly martensitic phase with $80-99 \%$ porosity) can sustain $10^{6}$ compression fatigue cycles with a stress up to $1.4 \times$ the yield strength for denser parts with closed porosity ${ }^{61,62}$ However, for NiTi porous structures, there is not yet much reliable fatigue data in the literature. One difficulty with fatigue measurements of open-porous structures is a lack of understanding of the role of surface porosity and roughness for complex geometries, which may significantly alter the obtainable fatigue properties.

\section{Biological aspects of laser AM of bulk and porous structures}

The biological aspects of NiTi alloys have been widely investigated due to their potential for a wide array of applications in the biomedical industry. In laser AM of NiTi biomedical devices, several factors need to be considered and clarified, as some are described next.

\section{Corrosion and biocompatibility of NiTi surfaces after laser irradiation}

In a simulated body-fluid solution, NiTi alloys generally demonstrate excellent corrosion resistance, comparable to $\mathrm{Ti}$ and Ti-6Al-4V materials. ${ }^{63}$ This corrosion resistance and biocompatibility is due to the presence of a Ti oxide film on the NiTi surfaces. This film acts as a protective layer, preventing allergic and toxic interactions such as $\mathrm{Ni}$ ion release (an important toxicity concern for NiTi parts). Thicker $\mathrm{TiO}_{2}$-based films minimize the nickel release and improve the biocompatibility of the material. ${ }^{64}$

The passive, protective oxide layer on the surface on $\mathrm{NiTi}$ parts can be altered by laser irradiation. Nd-YAG laser irradiation has been shown to improve NiTi corrosion resistance, and it reduces nickel ion release rate without affecting the overall 


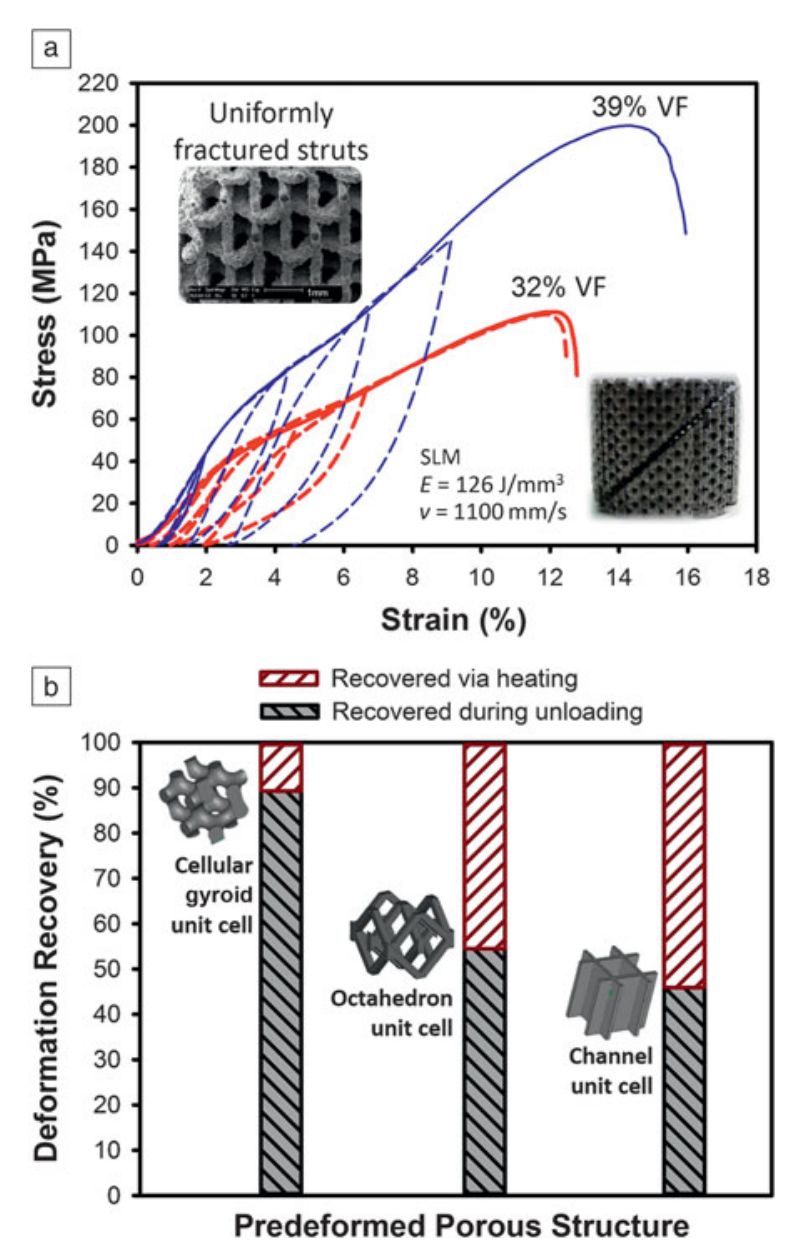

Figure 6. Compression behavior and deformation recovery of selective laser melting (SLM)-produced $\mathrm{NiTi}$ (55.2 wt\% Ni) porous structures. (a) Compressive stress-strain curves and loading-unloading behaviors (dashed plots) of porous structures with octahedron design and open/interconnected porosity at different solid volume fractions (\%VF). Notice the high springback of the porous structures, engineered by the SLM parameters. Note: $E$, laser-energy density; $v$, scan speed. ${ }^{38}$ (b) Effect of porous structure unit-cell design on shape-memory response and deformation recovery after $4 \%$ compressive strain. All samples are made using the same SLM processing parameters and the same structural VF (10\%). Source: KU Leuven.

bulk mechanical and physical properties, owing to a thickened passive surface film. ${ }^{65,66}$ Likewise, widely used metal AM fiber lasers (based on optical fibers doped with rare-earth elements) have been shown to improve biocompatibility and mesenchymal stem cells response (mesenchymal stem cells or MSCs are a cell type typically used in tissue engineering applications to assess a material's bioactivity) due to their positive influence on the surface properties (increased roughness, topography, and surface chemistry). ${ }^{67}$ Laser AM parameters (such as laser power) can also influence the corrosion resistance and biocompatibility of NiTi parts. ${ }^{58,66}$ These results and discussion promise improved biological surface properties of NiTi biomedical devices formed by AM technology.

\section{Biological response of bulk and porous laser AM-produced NiTi devices}

Recent analysis has demonstrated that both bulk and porous SLM-made NiTi samples are viable hosts for human stem cells. Figure 7 shows a SLM NiTi porous scaffold exposed to eight days of cell culture. After the cell culture, the porous scaffold is uniformly covered with a layer of viable cells (fluorescing green) despite the presence of a few dead cells (red fluorescence), as observed in Figure 7c. ${ }^{39}$ Similar reports on SLM-made NiTi porous structures confirm successful osteogenic cell activity of stem cells (adipose-derived stem cell type) in a salty medium or even under controlled compression loading. ${ }^{68}$

$\mathrm{Ni}$ ion release is another important biological aspect, and was found to be below cytotoxic concentrations for both bulk and porous AM-produced NiTi devices. ${ }^{39,69}$ In terms of processing parameters, it has been found that a lower laser-beam diameter can decrease Ni release from SLM-made porous NiTi scaffolds. This is as a result of a reduction in the amount of loosely sintered particles adhered to outer surfaces. ${ }^{39}$

\section{Post-cleaning of laser AM-produced porous NiTi structures}

AM-produced NiTi porous structures may contain numerous adhering residual particles. This is a cause for concern as these particles might be released into the body. Post-cleaning techniques such as chemical or electrochemical etching are useful to remove the adhered particles. Etching protocols used for conventional NiTi components (such as etching via aggressive HF-based solutions) are applicable for AM-produced components as well. ${ }^{70,71}$ Figure 8 shows successful postcleaning of a SLM-made NiTi porous structure, as no remaining residual particles can be observed on surfaces after etching with the used HF-based reagent (see Figure 8b).

\section{Design considerations to improve biological properties of NiTi structures}

Among all manufacturing techniques for NiTi structures, AM techniques provide the highest design freedom. This allows for superior biomedical designs (e.g., patient-specific porous structures) with high biomechanical compatibility and flexible permeability. ${ }^{72-74}$ In general, cell proliferation is favored in regions of smooth curvature (without sharp angles) ${ }^{75}$ in porous designs providing improved permeability (a determinant factor for cell and nutrition mass transport). ${ }^{74,76,77}$

Apart from porous structure permeability, NiTi alloys exhibit superior mechanical compatibility with bone (compared to other biologically compatible metals such as stainless steel and Ti-6Al-4V). ${ }^{78}$ Therefore, AM-produced NiTi biomedical devices can be designed with maximum biomechanical and physiological compatibility for a specific patient. This minimizes undesirable bone-implant interactions (such as mechanical mismatch, stress shielding, and implant failure), reducing the patient healing period and improving the lifetime performance of the implant. 


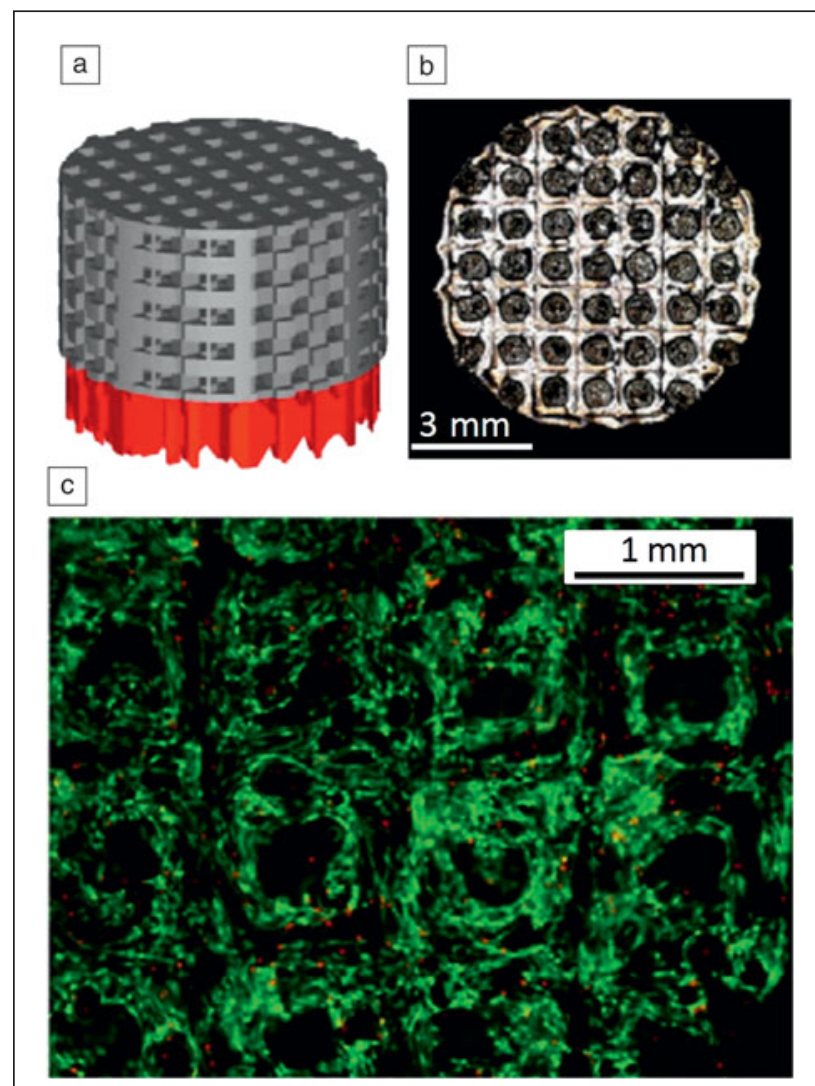

Figure 7. (a) Original computer-aided design file for a porous specimen and (b) top surface of the selective laser melting-produced porous NiTi sample. (c) Living cells (green) with a negligible minority of dead cells (red) in fluorescence micrographs of the corresponding NiTi sample after culturing human mesenchymal stem cells for eight days. Reprinted with permission from Reference 39. (c) 2013 Elsevier.

\section{Nonstandard NiTi-based alloys made by laser AM methods}

One great advantage of laser AM processes is the capacity to customize powder compositions by introducing secondary phases. For example, SLM has been used to manipulate NiTi properties by adding hydroxyapatite (an excellent bone bioactive material) to produce a composite for biomedical applications. ${ }^{79}$ Furthermore, LMD has been utilized to produce a ductile and wear-resistant in situ $\mathrm{TiB}_{2} / \mathrm{NiTi}$ coating (to increase durability of Ti-6Al-4V alloy) from a powder mixture of $\mathrm{Ni}+\mathrm{TiB}_{2}+\mathrm{Ti}^{80,81}$ or even to generate a functionally graded Ti-NiTi to customize corrosion and mechanical behavior. ${ }^{82}$ These are promising aspects that can potentially improve the efficiency of functional components.

\section{Potential biomedical applications of laser AM-produced NiTi components}

The biomedical industry is a key driver, among others (in particular, aerospace, robotics, and actuators), for the market growth of shape-memory NiTi alloys (for use in biomedical devices such as orthopedic implants, stents, filters, retrieval baskets, dental, and surgical tools). This interest originates from NiTi shape-memory behavior (e.g., thermal memory can trigger post-implantation fitting or superelasticity can provide highly elastic metal devices), along with good biocompatibility, bending and corrosion resistance, biomechanical and physiological compatibility, fatigue performance, and magnetic resonance compatibility of $\mathrm{NiTi}^{2,78,83}$ The demand for $\mathrm{NiTi}$ components will logically grow further after applying AM to fabricate quality and complex NiTi components.

Figure 9 illustrates some applications of NiTi biomedical tools that can be potentially manufactured using AM techniques. Figure 9a shows a surgical NiTi implant used as stiffness alterable osteosynthetic plates (for holding fractured bones together during healing), which allow implant stiffness to be altered over the course of healing, for instance, to bear more weight at an earlier stage. The stiffness is altered using an induction device, triggering the shape-memory effect at a desirable date after implantation and straightening the deformed outer sheet. Such complex implants have been previously made by the application of laser cutting and welding, ${ }^{19}$ while they can be manufactured in one step using AM technology.

Figure $9 \mathrm{~b}$ demonstrates an orthopedic fixator (a surgical implant used to aid bone healing) that can be fitted to the outer bone body via the shape-memory effect. ${ }^{84}$ Using AM,

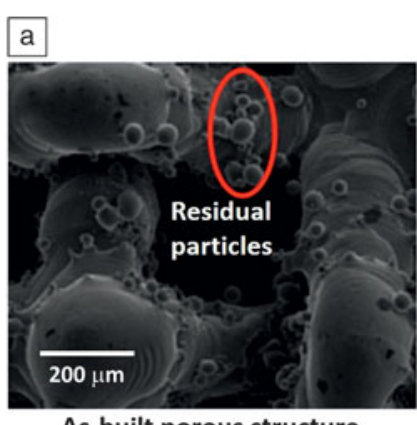

As-built porous structure

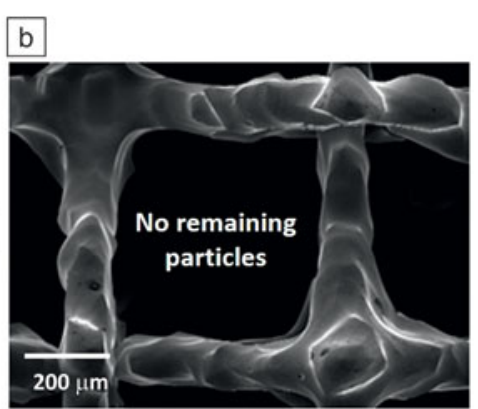

Cleaned SLM-made porous structure

Figure 8. Scanning electron microscope images of a selective laser melting (SLM)produced NiTi porous structure. (a) As-built surfaces containing adhered particles. (b) Porous structure after chemical etching (2 min etching using a $\mathrm{HF}: \mathrm{HNO}_{3}: \mathrm{H}_{2} \mathrm{O}=1: 2: 3$ solution), showing no remaining/adhered particles. Source: KU Leuven.

customized NiTi orthopedic fixators could be manufactured for each individual patient to provide better dimensional fitting. Figure $9 \mathrm{c}-\mathrm{d}$ exhibit shape-memory bone fixation devices ${ }^{85}$ for traumatic surgery that can be potentially manufactured in a patient-customized manner using AM techniques. Such customization is aimed at improving the fixation and direction of shape-memory forces to facilitate surgery and shorten the healing period.

Figure $9 \mathrm{e}-\mathrm{f}$ shows porous permeable implants for vertebral surgery. ${ }^{85}$ Such porous implants can be fabricated using AM technology after customization based on patient MRI data. These NiTi porous implants/scaffolds allow maximum biological permeability (for both cell 

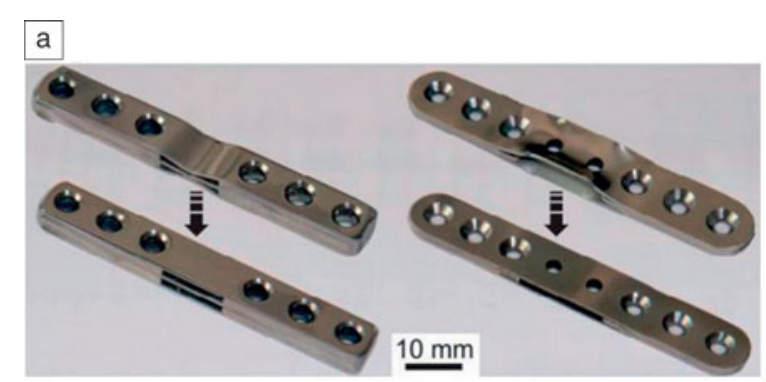

b

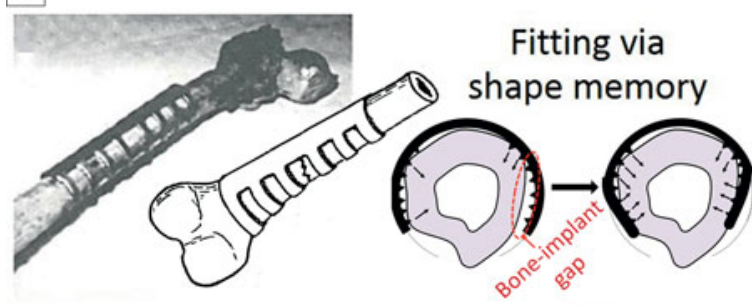

c
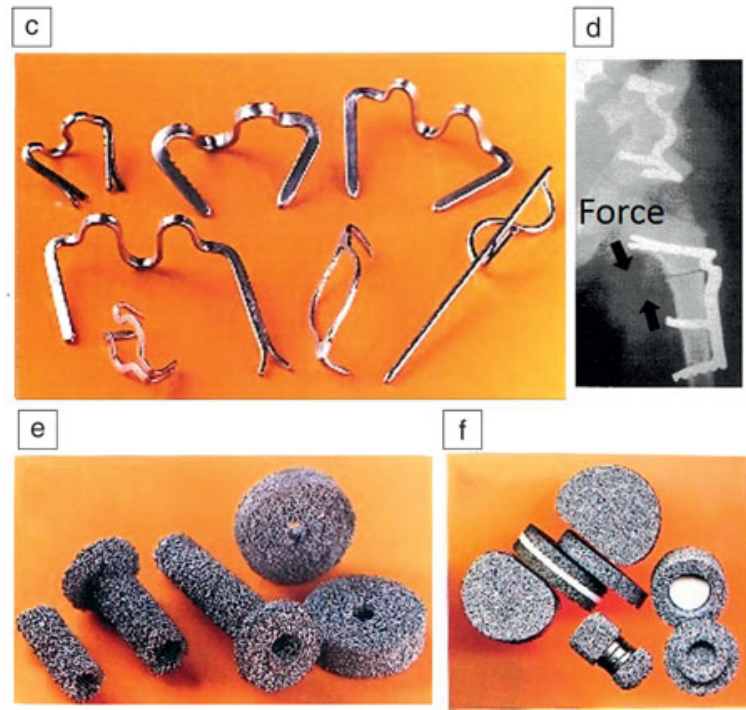

Figure 9. Conventionally manufactured biomedical components where additive manufacturing can be potentially applied to fabricate NiTi devices. (a) Surgical implant where triggering the shape memory leads to straightening of the outer $\mathrm{NiTi}$ sheets adapting the bending stiffness of the implant. (b) Sawtooth arm embracing orthopedic fixator that can hold the fractured bone, after being fitted to the outer bone body via shape-memory effect. (c-d) A set of shape-memory implants for traumatic surgery applied to $\mathrm{pin} / \mathrm{hold} /$ press the fractured bones together. (e-f) A set of porous permeable implants for vertebral surgery. (a) Reprinted with permission from Reference 19. (c) 2013 Elsevier. (b) Adapted with permission from Reference 84. (C) 2000 Springer. (c-f) Reprinted with permission from Reference 85. (c) 2000 STT Publishing.

adhesion and nutrient transport), excellent mechanical compatibility, and optimal dimensional fitting.

Figure 10 shows some examples of NiTi devices manufactured using AM technology. Figure 10a displays some SLMproduced sawtooth orthopedic devices that can be used to staple or pin fractured bones together. Figure 10b shows a reconstructed 3D model of a jaw that has been used to manufacture
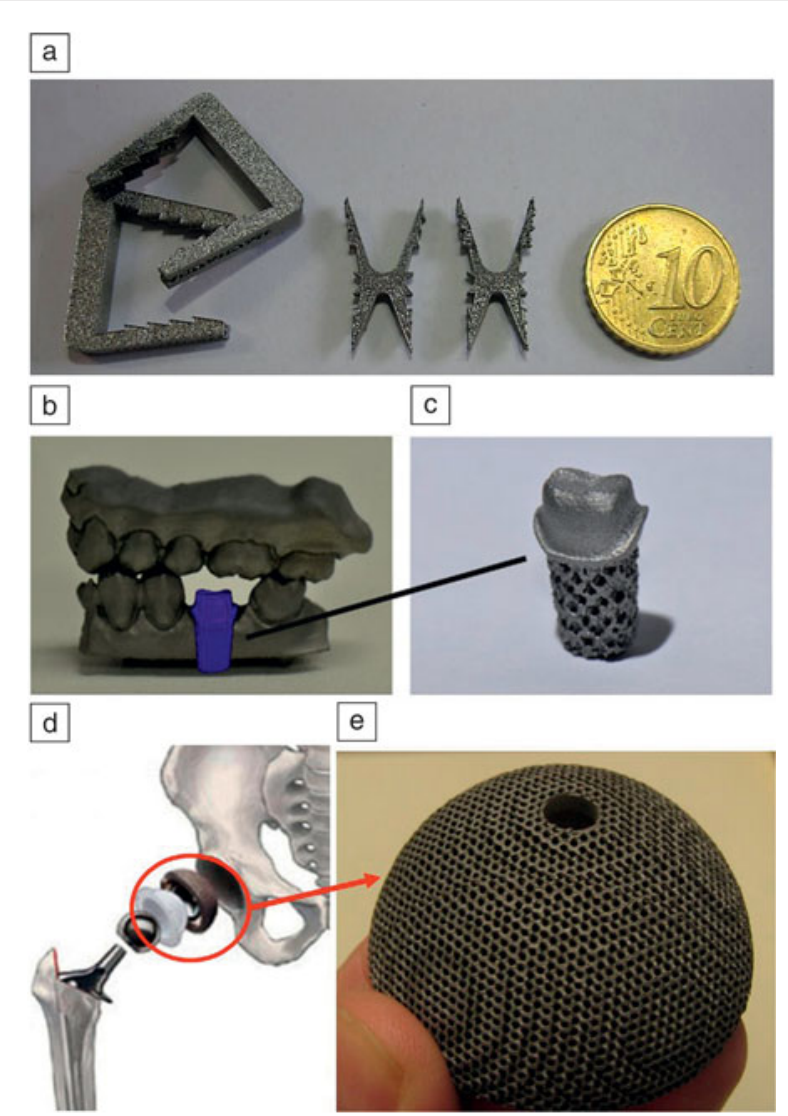

Figure 10. Selective laser melting-produced NiTi biomedical components showing the potential of this technology for medical industry. (a) Sawtooth orthopedic staples/pins.

(b) Schematic of a computer-aided design model of a tooth root inserted in a lower-jaw segment. (c) The corresponding porous NiTi root. (d) A hip implant for insertion into the right femur. (e) Corresponding NiTi implant (an acetabular cup) designed with biomedical porosity. (a) Source: KU Leuven. (b-c) Reproduced with permission from Reference 55. (C) 2014 IOP Publishing.

(d) Adapted with permission from Reference 86. (C) 2011 Elsevier. (e) Source: KU Leuven.

a porous NiTi tooth root (Figure 10c). ${ }^{55}$ Figure 10d-e demonstrates a hip implant that has to be fitted into the hip bone of the patient, in which the cup-shaped NiTi component is fabricated using SLM. ${ }^{86}$ In general, AM can successfully fabricate such NiTi porous devices, allowing for optimal fitting (via shapememory effect and patient customization) and maximum biological compatibility (e.g., via biocompatible porous structure).

\section{Summary}

This article summarized current progress in laser AM of NiTi alloys. The most exciting feature is the possibility of manipulating the shape-memory behavior of AM-produced NiTi components. For instance, through adjusting laser-processing parameters (e.g., scanning speed and laser-energy density), transformation temperatures and hence final microstructure can be altered. On the other hand, the design freedom afforded by AM enables the manufacture of complex geometries (such as porous 
structures with repeatable unit cells) that may change the shapememory behavior of the component. This enables engineering/ customizing the desired functional property (i.e., shape-memory effect or, in contrast, superelasticity) according to any specific application.

Prior to laser AM application in manufacturing NiTi components, various microstructural, mechanical, and even biological laser AM influences should be recognized. For example, SLM microstructure of NiTi components may consist of small subgrains (formed and textured within laser tracks) in conjunction with large stress-stimulated martensitic phases. This microstructure influences the mechanical behavior, including the shape-memory response. Besides microstructure, the mechanical properties are altered with the solid volume fraction of porous components, allowing tailored strength/stiffness especially for patient-specific porous biomedical implants.

In term of biological properties, laser treatment can enhance the corrosion resistance and biocompatibility through a thicker-surface oxide film, despite some adhered particles that may necessitate post-cleaning protocols. Furthermore, the toxicity and $\mathrm{Ni}$ ion release of AM manufactured bulk and porous implants have been reported to be well below cytotoxic concentrations. These excellent biocompatibility aspects have been confirmed by the good adherence and rapid growth of cultured cells on AM-made NiTi parts. As AM design freedom opens the pathway for low volume or mass customization, this article also provided potential examples where biomedical NiTi devices can be made using AM techniques (e.g., patient specific bulk/porous surgical and dental implants).

\section{Acknowledgments}

We would like to thank A. Ahadi (National Institute for Materials Science, Tsukuba, Japan) for preparation of this work, as well as financial support from the Flemish IWT-MultiMet Project (No. 150010) and EU BioTiNet Project (Grant No. 264635, under the EU Marie Curie ITN Project).

\section{References}

1. J. Van Humbeeck, Mater. Sci. Eng. A 273, 134 (1999).

2. T. Duerig, A. Pelton, D. Stöckel, Mater. Sci. Eng. A 273, 149 (1999).

3. D.S. Levi, N. Kusnezov, G.P. Carman, Pediatr. Res. 63, 552 (2008).

4. J. Mohd Jani, M. Leary, A. Subic, M.A. Gibson, Mater. Des. 56, 1078 (2014).

5. K. Otsuka, X. Ren, Intermetallics 7, 511 (1999).

6. C. Liu, H. Qin, P.T. Mather, J. Mater. Chem. 17, 1543 (2007).

7. K. Otsuka, T. Kakeshita, MRS Bull. 27, 91 (2002).

8. S. Barbarino, E.I.S. Flores, R.M. Ajaj, I. Dayyani, M.I. Friswell, Smart Mater. Struct. 23, 063001 (2014)

9. S. Nemat-Nasser, W.-G. Guo, Mech. Mater. 38, 463 (2006).

10. B. Ye, B.S. Majumdar, I. Dutta, Acta Mater. 57, 2403 (2009).

11. K. Bhattacharya, R.V. Kohn, Acta Mater. 44, 529 (1996).

12. M.R. Daymond, M.L. Young, J.D. Almer, D.C. Dunand, Acta Mater. 55, 3929 (2007).

13. S. Dadbakhsh, B. Vrancken, J.-P. Kruth, J. Luyten, J. Van Humbeeck, Mater. Sci. Eng. A 650, 225 (2016).

14. S.E. Bishara, R.D. Barrett, M.I. Selim, Am. J. Orthod. Dentofacial Orthop. 103, 115 (1993)

15. O. Prymak, D. Bogdanski, M. Köller, S.A. Esenwein, G. Muhr, F. Beckmann, T. Donath, M. Assad, M. Epple, Biomaterials 26, 5801 (2005).

16. A. Bansiddhi, T.D. Sargeant, S.I. Stupp, D.C. Dunand, Acta Biomater. 4, 773 (2008).

17. R.D. Barrett, S.E. Bishara, J.K. Quinn, Am. J. Orthod. Dentofacial Orthop. 103, 8 (1993).
18. M.T. Andani, N. Shayesteh Moghaddam, C. Haberland, D. Dean, M.J. Miller, M. Elahinia, Acta Biomater. 10, 4058 (2014).

19. R. Pfeifer, C.W. Müller, C. Hurschler, S. Kaierle, V. Wesling, H. Haferkamp, Procedia CIRP 5, 253 (2013).

20. C. Lexcellent, "The World of Shape-Memory Alloys," in Shape-Memory Alloys Handbook (Wiley, Hoboken, NJ, 2013), p. 11.

21. D.E. Hodgson, M.H. Wu, R.J. Biermann, "Shape Memory Alloys," in ASM Handbook, Volume 2, Properties and Selection, Nonferrous Alloys and SpecialPurpose Materials (ASM International, Materials Park, OH 1990), p. 897.

22. M.H. Elahinia, M. Hashemi, M. Tabesh, S.B. Bhaduri, Prog. Mater. Sci. 57, 911 (2012).

23. W. Yan, Mater. Sci. Eng. A 427, 348 (2006)

24. L. Yan, Y. Liu, J. Mater. Res. 30, 186 (2015).

25. K. Otsuka, X. Ren, Prog. Mater. Sci. 50, 511 (2005).

26. ASTM International, "ASTM F2063-00" (2000), available at http://www.astm. org/DATABASE.CART/HISTORICAL/F2063-00.htm.

27. J. Frenzel, E.P. George, A. Dlouhy, C. Somsen, M.F.X. Wagner, G. Eggeler, Acta Mater. 58, 3444 (2010).

28. J. Khalil-Allafi, B. Amin-Ahmadi, J. Alloys Compd. 487, 363 (2009).

29. S. Dadbakhsh, M. Speirs, J.-P. Kruth, J. Schrooten, J. Luyten, J. Van Humbeeck, Adv. Eng. Mater. 16, 1140 (2014).

30. Y. Motemani, M. Nili-Ahmadabadi, M.J. Tan, M. Bornapour, S. Rayagan, J. Alloys Compd. 469, 164 (2009)

31. Y. Liu, Z.L. Xie, J. Van Humbeeck, L. Delaey, Acta Mater. 47, 645 (1999)

32. J. Frenzel, Z. Zhang, K. Neuking, G. Eggeler, J. Alloys Compd. 385, 214 (2004).

33. K. McNamara, J. Butler, A.A. Gandhi, S.A.M. Tofail, in Reference Module in Materials Science and Materials Engineering (Elsevier, Amsterdam, 2016).

34. K. Weinert, V. Petzoldt, Mater. Sci. Eng. A 378, 180 (2004).

35. J.-T. Yeom, J.H. Kim, J.-K. Hong, S.W. Kim, C.-H. Park, T.H. Nam, K.-Y. Lee, Mater. Res. Bull. 58, 234 (2014)

36. T. Bormann, R. Schumacher, B. Müller, M. Mertmann, M. Wild, J. Mater. Eng. Perform. 21, 2519 (2012).

37. A.T. Clare, P.R. Chalker, S. Davies, C.J. Sutcliffe, S. Tsopanos, Int. J. Mech. Mater. Des. 4, 181 (2008).

38. S. Dadbakhsh, M. Speirs, J.-P. Kruth, J. Van Humbeeck, CIRP Ann. 64, 209 (2015).

39. T. Habijan, C. Haberland, H. Meier, J. Frenzel, J. Wittsiepe, C. Wuwer, C. Greulich, T.A. Schildhauer, M. Köller, Mater. Sci. Eng. C 33, 419 (2013).

40. I. Shishkovsky, I. Yadroitsev, I. Smurov, Phys. Procedia 39, 447 (2012).

41. H. Kyogoku, J.A. Ramos, D.L. Bourell, Proc. 14th Solid Freeform Fabr. Symp. (The University of Texas at Austin, Austin, TX, 2003), p. 668.

42. B.V. Krishna, S. Bose, A. Bandyopadhyay, Metall. Mater. Trans. A 38, 1096 (2007).

43. A. Bandyopadhyay, B.V. Krishna, W. Xue, S. Bose, J. Mater. Sci. 20, S29 (2009).

44. M.N. Mokgalaka, S.L. Pityana, P.A.I. Popoola, T. Mathebula, Adv. Mater. Sci. Eng. ID 363917 (2014).

45. S. Khademzadeh, N. Parvin, P.F. Bariani, Int. J. Precis. Eng. Manuf. 16, 2333 (2015).

46. W.E. Frazier, J. Mater. Eng. Perform. 23, 1917 (2014).

47. "Optomec Launches New 3D Printer for Metal Additive Manufacturing" (3Ders, 2013), http://www.3ders.org/articles/20130612-optomec-launches-new-3d-printerfor-metal-additive-manufacturing.html.

48. J.-P. Kruth, S. Dadbakhsh, B. Vrancken, K. Kempen, J. Vleugels, J.V. Humbeeck, "Additive Manufacturing of Metals via Selective Laser Melting," in Additive Manufacturing, T.S. Srivatsan, T.S. Sudarshan, Eds. (CRC Press, Boca Raton, FL, 2015), p. 69.

49. J. Walker, M. Elahinia, C. Haberland, Proc. ASME 2013 Conf. Smart Mater., Adaptive Struct. Intell. Syst. (Snowbird, UT, 2013), p. 1.

50. T. Bormann, B. Müller, M. Schinhammer, A. Kessler, P. Thalmann, M. de Wild, Mater. Charact. 94, 189 (2014).

51. S. Saedi, A.S. Turabi, M.T. Andani, C. Haberland, M. Elahinia, H. Karaca, Smart Mater. Struct. 25, 035005 (2016).

52. S. Saedi, A.S. Turabi, M.T. Andani, C. Haberland, H. Karaca, M. Elahinia, J. Alloys Compd. 677, 204 (2016)

53. I.V. Shishkovsky, I.A. Yadroitsev, I.Y. Smurov, Tech. Phys. Lett. 39, 1081 (2013).

54. B. Zhang, J. Chen, C. Coddet, J. Mater. Sci. Technol. 29, 863 (2013).

55. C. Haberland, M. Elahinia, J.M. Walker, H. Meier, J. Frenzel, Smart Mater. Struct. 23, 104002 (2014).

56. S. Khademzadeh, S. Carmignato, N. Parvin, F. Zanini, P.F. Bariani, Mater. Des. 90, 745 (2016).

57. P.R. Halani, Y.C. Shin, Metall. Mater. Trans. A 43, 650 (2012).

58. J.J. Marattukalam, A.K. Singh, S. Datta, M. Das, V.K. Balla, S. Bontha, S.K. Kalpathy, Mater. Sci. Eng. C 57, 309 (2015).

59. K. Malukhin, K. Ehmann, J. Manuf. Sci. Eng. 128, 691 (2006).

60. M.J. Mahtabi, N. Shamsaei, M.R. Mitchell, J. Mech. Behav. Biomed. Mater. 50, 228 (2015). 
61. S. Bernard, V. Krishna Balla, S. Bose, A. Bandyopadhyay, J. Mech. Behav. Biomed. Mater. 13, 62 (2012).

62. S. Bernard, V.K. Balla, S. Bose, A. Bandyopadhyay, Mater. Sci. Eng. C 31, 815 (2011)

63. N. Figueira, T.M. Silva, M.J. Carmezim, J.C.S. Fernandes, Electrochim. Acta 54, 921 (2009)

64. V. Muhonen, R. Heikkinen, A. Danilov, T. Jämsä, J. Tuukkanen, J. Mater. Sci. 18, 959 (2007)

65. H.C. Man, Z.D. Cui, T.M. Yue, Scr. Mater. 45, 1447 (2001)

66. Z.D. Cui, H.C. Man, X.J. Yang, Surf. Coat. Technol. 192, 347 (2005).

67. C.W. Chan, I. Hussain, D.G. Waugh, J. Lawrence, H.C. Man, Mater. Sci. Eng. C 42, 254 (2014).

68. S. Strauß, S. Dudziak, R. Hagemann, S. Barcikowski, M. Fliess, M. Israelowitz, D. Kracht, J.W. Kuhbier, C. Radtke, K. Reimers, P.M. Vogt, PLoS One 7, e51264 (2012)

69. J.L.M. Putters, D.M.K.S. Kaulesar Sukul, G.R. de Zeeuw, A. Bijma, P.A. Besselink, Eur. Surg. Res. 24, 378 (1992).

70. N. Munroe, C. Pulletikurthi, W. Haider, J. Mater. Eng. Perform. 18, 765 (2009).

71. S. Shabalovskaya, J. Anderegg, J. Van Humbeeck, Acta Biomater. 4, 447 (2008).

72. T.B. Sercombe, X. Xu, V.J. Challis, R. Green, S. Yue, Z. Zhang, P.D. Lee, Mater. Des. 67, 501 (2015)

73. X. Wang, S. Xu, S. Zhou, W. Xu, M. Leary, P. Choong, M. Qian, M. Brandt, Y.M. Xie, Biomaterials 83, 127 (2016).
74. S. Truscello, G. Kerckhofs, S. Van Bael, G. Pyka, J. Schrooten, H. Van Oosterwyck, Acta Biomater. 8, 1648 (2012)

75. S. Van Bael, Y.C. Chai, S. Truscello, M. Moesen, G. Kerckhofs, H. Van Oosterwyck, J.-P. Kruth, J. Schrooten, Acta Biomater. 8, 2824 (2012).

76. M.R. Dias, P.R. Fernandes, J.M. Guedes, S.J. Hollister, J. Biomech. 45, 938 (2012).

77. Z. Zhang, D. Jones, S. Yue, P.D. Lee, J.R. Jones, C.J. Sutcliffe, E. Jones, Mater. Sci. Eng. C 33, 4055 (2013).

78. L. Petrini, F. Migliavacca, J. Metall. 2011, ID 501483 (2011).

79. I.V. Shishkovskii, I.A. Yadroitsev, I.Y. Smurov, Powder Metall. Met. Ceram. 50, 275 (2011)

80. Y. Lin, Y. Lei, H. Fu, J. Lin, J. Mater. Eng. Perform. 24, 3717 (2015).

81. Y. Lin, Y. Lei, H. Fu, J. Lin, Mater. Des. 80, 82 (2015).

82. T.E. Abioye, P.K. Farayibi, P. Kinnel, A.T. Clare, Int. J. Adv. Manuf. Technol. 79, $843(2015)$

83. D. Tarnita, D. Tarnita, D. Bolcu, "Orthopaedic Modular Implants Based on Shape Memory Alloys," in Biomedical Engineering — From Theory to Applications, R. Fazel, Ed. (InTech, 2011).

84. K. Dai, "Ti-Ni-Mo Shape-Memory Alloys for Medical Applications," in Shape Memory Implants, L. Yahia, Ed. (Springer Berlin, Heidelberg, 2000), p. 105.

85. V.E. Gunther, Delay Law and New Class of Materials and Implants in Medicine (STT Publishing, Northampton, MA, 2000).

86. A. Saigal, M. Fonte, Mater. Sci. Eng. A 528, 5551 (2011).

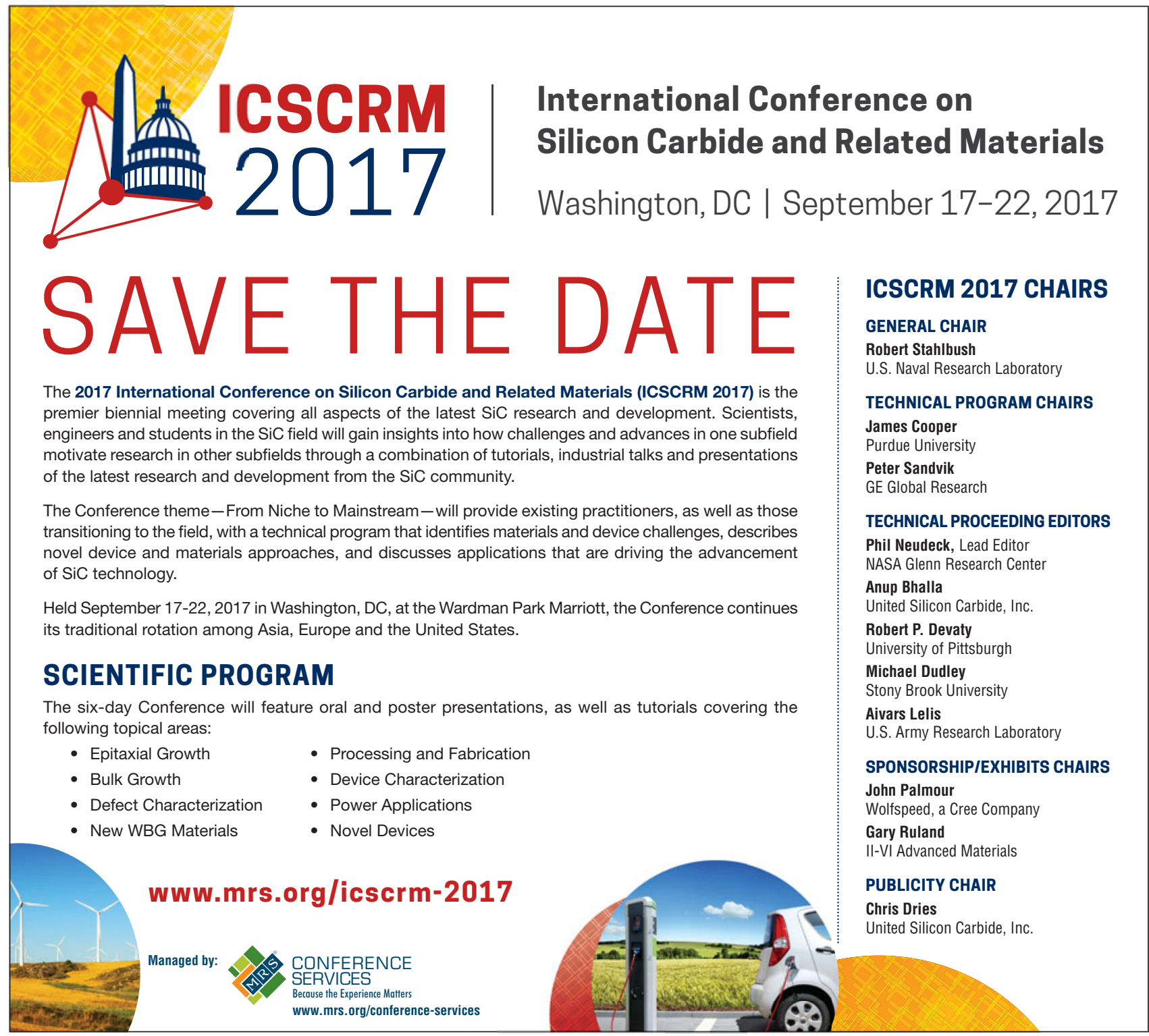

